\title{
Theoretical Investigation of New Organic Electroluminescent Materials Based on 4-Azaindole Groups and Oligopyrrole
}

\section{Ibeji $\mathrm{CU}^{1 *}$, Okpala $\mathrm{EO}^{2}$, Adejoro $\mathrm{IA}^{2}$ and Onyia $\mathrm{KK}^{1}$}

${ }^{1}$ Department of Pure and Industrial Chemistry, University of Nigeria, Nsukka, Enugu, Nigeria ${ }^{2}$ Department of Chemistry, University of Ibadan, Ibadan, Nigeria

\begin{abstract}
The electronic properties of four new organic compounds (I-IV) were studied theoretically for application as hole-transporting materials in electroluminescent (EL) devices. We investigated theoretically, the effect of increasing number of pyrrole rings between 4-azainole end moieties. The time dependent density functional theory (TD-DFT/ B3LYP/6-31G(d)) calculated energy gap (E-gap) of the studied compounds decreases in the order of $|>||>|||>\mid V$; the significant reduction of E-gap of compound IV with $2.7 \mathrm{eV}$ compared to $4.27 \mathrm{eV}$ of compound II is due to the bridging effect of $\mathrm{C}=\mathrm{C}\left(\mathrm{CO}_{2} \mathrm{H}\right)_{2}$ which remove the steric effect, caused by high dihedral angle between two central pyrrole rings in the non-bridged II. Compound IV possess low-lying lowest occupied molecular orbital(LUMO) energy levels and low lying highest occupied molecular orbital (HOMO) energy levels, may be promising candidate for hole transporting and bright blue to red emitting layer in organic light emitting device (OLED) fabrication.
\end{abstract}

Keywords: Hole-transporting material; Electroluminescent device; Organiclight emitting device; Photoluminescence; Chemical structures

\section{Introduction}

The study of organic electroluminescence (EL) materials is now a rapidly developing field of material science due to promising practical applications [1]. In spite of the impressing achievement of the last decade, the problem of searching for new effective organic luminescent materials of different emission colours is still topical. Recently, many electronic and optical-electronic devices consisting of organic materials have been demonstrated; organic light emitting devices (OLEDs) require lower energy input, have a wider viewing angle with improved colour contrast, and can be made much thinner. The use of $\pi$-conjugated organic compounds as electroluminescent materials in organic light-emitting devices (OLEDs) was originally introduced by Van Slyke over two decades ago [2,3]. Since then, the development of new $\pi$-conjugated compounds especially small molecules with superior physical, optical, thermal, and electrochemical properties has become one of the most reviving research areas [4]. Although many fluorescent blue emitters have been reported, such as anthracene derivatives, phenylene derivatives, pyrene derivatives, fluorene derivatives, carbazolederivaties, triarylamine derivatives, and phosphorescent iridium complexes, there is still a clear need for further improvements in terms of efficiency and colour purity compared to red and green emitters [5].

A new type of luminescent compounds based on Oligomers and azaindolyl groups were prepared by Hong et al. [5]. The presence of 4-azainole moieties at the end group of oligopyrrole greatly enhanced the photoluminescence by increasing the intrinsic stiffness of the polymer backbone; weaken intermolecular interaction [6-8]. The emission spectrum of a conjugated polymer depends basically on its $\pi-\pi^{*}$ band gap, which can be tailored using different structures. In this paper, we present a theoretical study of four new organic electroluminescent material (IIV) based on (4-azaindolyl) oligopyrrole. We investigated theoretically, the effect of increasing pyrrole ring on 4-azainole moieties on the structural and optical-electronic properties of the compounds. Then, bridging effect was studied by bridging two central pyrrole rings with electron withdrawing 2-carboxylpropenoic acid group $\left[\mathrm{C}=\mathrm{C}\left(\mathrm{CO}_{2} \mathrm{H}\right)_{2}\right]$.

The chemical structures of the materials studied are shown in Figure 1.

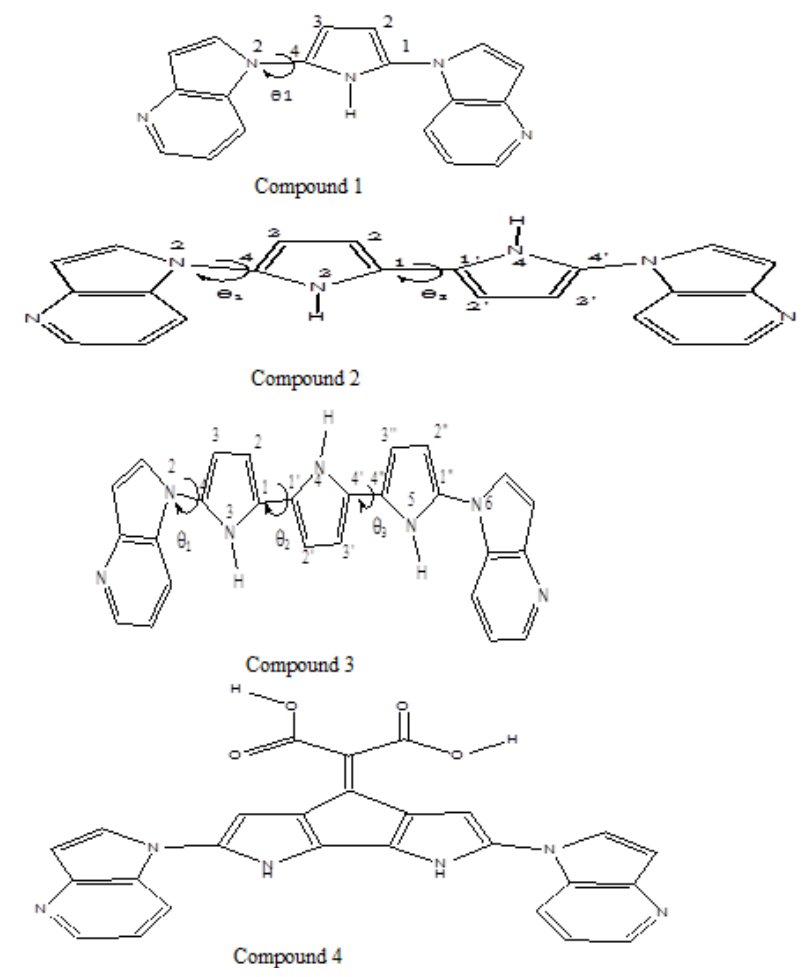

Figure 1: Chemical structures of the studied compounds.

*Corresponding author: Ibeji CU, Department of Pure and Industrial Chemistry, University of Nigeria, Nsukka, Enugu, Nigeria, Tel: +2349057924426; E-mail: ugochukwu.ibeji@unn.edu.ng

Received May 20, 2016; Accepted June 07, 2016; Published June 13, 2016

Citation: Ibeji CU, Okpala EO, Adejoro IA, Onyia KK (2016) Theoretical Investigation of New Organic Electroluminescent Materials Based on 4-Azaindole Groups and Oligopyrrole. J Appl Computat Math 5: 307. doi:10.4172/2168-9679.1000307

Copyright: ( 2016 Ibeji CU, et al. This is an open-access article distributed under the terms of the Creative Commons Attribution License, which permits unrestricted use, distribution, and reproduction in any medium, provided the original author and source are credited. 


\section{Computational Method}

Quantum chemical calculation of the ground state molecular structures of (I-IV) were performed using the Spartan'14 program package on HP 2000 inter (R) core (TM) i3-3110 (M) CPU @ $2.40 \mathrm{GHz}$ processor machine (computer) having 6.00 GB installed memory (RAM) and $750 \mathrm{~GB}$ hard disc. The molecules were drawn with SPARTAN' 14 graphical user interface (GUI) and the energy minimization conducted using MMFFaq (Merck Molecular Force Field). MMFFaq, Molecular Mechanics Conformational Distribution gave rise to different conformers for each of the studied compounds with their corresponding energies. The most stable conformer (i.e. conformer with the lowest energy) obtained for each compounds were submitted into SPARTAN' 14 for energy optimization. The influence of increasing number of pyrrole rings on the opto-electronic properties of all the studied compounds were fully optimized at Density Functional Theory (Becke's Three Parameter Hybrid Functional using the Lee, Yang and Parr Correlation Functional-B3LYP) [8]. The basis sets: 6-31G (d) and EDF2 were used for all atoms. We have also examined HOMO and LUMO energies levels; the energy gap is evaluated as the difference between the HOMO and LUMO energies. The electronic transition properties, which include the maximum excitation wavelength $\left(\lambda_{\max }^{\text {abs }}\right)$, excitation energy, relative intensities (oscillating strength), molecular orbitals character and coefficient of the compounds, were studied using Time Dependent Density Functional Theory (TD-DFT) [9]

\section{Results}

\section{Optical-electronic properties}

The electronic properties of all the studied compounds were obtained by DFT calculations at B3LYP/6-31G (d) and EDF2/6-31G (d) levels. Table 1, Figures 2 and 3 show the analysis of HOMO-LUMO energy gap of the studied compounds.

Highest occupied molecular orbital (HOMO) represents the ability to donate an electron and negative values of HOMO energy is taken as the ionization potential. Using Polarized basis set of B3LYP/6-31G (d), it was found that ionization potential gradually decreased with increasing of the $\pi$-conjugation system. The HOMO energy levels of these materials were in the range of -5.75 to $-4.83 \mathrm{eV}$, matching well with most work function of indium tin oxide (ITO) electrode and favouring the injection and transport of holes. Their LUMO energy levels were in the range of- 0.91 to $-0.81 \mathrm{eV}$.The HOMO-LUMO energy gaps were calculated to be decreased from $4.84 \mathrm{eV}$ to $4.02 \mathrm{eV}$ with an increase in

\begin{tabular}{|l|c|c|c|}
\hline & E-LUM0 (eV) & E-HOMO (eV) & E-gap (eV) \\
\hline Compound I $(n=1)$ & & & \\
\hline B3LYP/6-31G(d) & -0.91 & -5.75 & 4.84 \\
\hline EDF2/6-31G(d) & -1 & -5.57 & 4.57 \\
\hline Compound II (n=2) & & & \\
\hline B3LYP/6-31G(d) & -0.85 & -5.12 & 4.27 \\
\hline EDF2/6-31G(d) & -0.94 & -4.98 & 4.04 \\
\hline Compound III (n=3) & & & \\
\hline B3LYP/6-31G(d) & -0.81 & -4.83 & 4.02 \\
\hline EDF2/6-31G(d) & -0.9 & -4.70 & 3.8 \\
\hline Compound IV (n=2) & & & \\
\hline Bridged with & & & 2.7 \\
\hline C=C(CO $\left.{ }_{2} H\right)_{2}$ & & & \\
\hline B3LYP/6-31G(d) & -2.46 & -5.16 & \\
\hline EDF2/6-31G(d) & -2.56 & -5.02 & \\
\hline n: Number of py/rom & & & \\
\hline
\end{tabular}

$\mathrm{n}$ : Number of pyrrole rings in the compound; eV: Electron volts; E-gap: LUMOHOMO; E: Energy

Table 1: Calculated HOMO (eV), LUMO (eV) and Energy gap (eV).

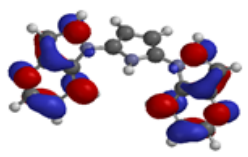

LUMO (I)

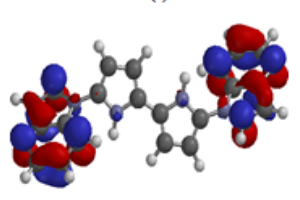

LUMO(II)

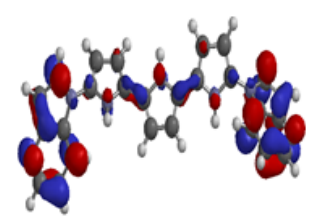

LUMO(III)

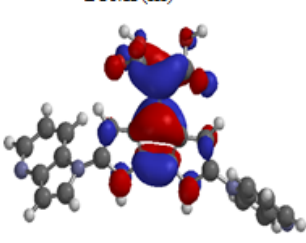

LUMO(IV)

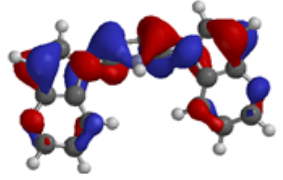

HOMO(I)

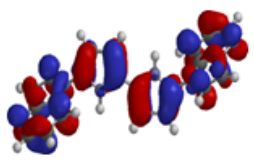

HOMO(II)

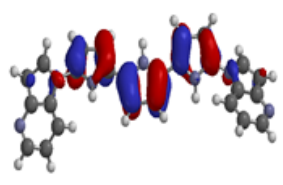

HOMO (III)

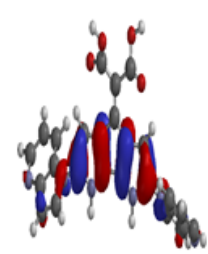

HOMO(IV)
Figure 2: The contour plots of HOMO and LUMO orbital of the studied compounds using DFT/B3LYP/6-31G (d).

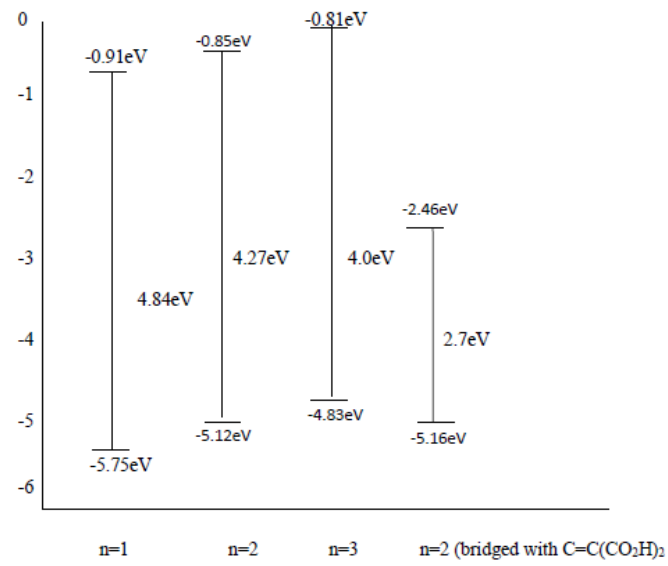

Figure 3: Sketch of B3LYP/6-31G(d) calculated energies of HOMO, LUMO levels of studied compounds.

the $\pi$-conjugation length of the oligopyrrole units of the compounds (1-3) and these values are in perfect accordance with those estimated from the electronic transition data [10-12].

The distribution of the highest occupied molecular orbital (HOMO) and the lowest unoccupied molecular orbital (LUMO) of studied compounds was also investigated at the DFT/B3LYP/ 6-31G (d) level for the geometry optimizations. The iso-density surface plot of HOMO and LUMO were exhibited above in Figure 2, it is seen from the figure that the electron density of HOMO is mainly localized on the pyrrolyl moieties while the electron density of LUMO is mainly on the 4-azaindole backbone except compound VI, where is localized on pyrrolyl groups with contribution from 2-carboxylpropenioc acid substituent group. The electron transition from the ground state to the excited state will be 
Citation: Ibeji CU, Okpala EO, Adejoro IA, Onyia KK (2016) Theoretical Investigation of New Organic Electroluminescent Materials Based on 4-Azaindole Groups and Oligopyrrole. J Appl Computat Math 5: 307. doi:10.4172/2168-9679.1000307

Page 3 of 4

\begin{tabular}{|c|c|c|c|c|c|}
\hline Electronic transition & $\lambda_{\text {abs }}(\mathrm{nm})$ & Eex. (eV) & O.S. & MO/character & Coefficient \\
\hline \multicolumn{6}{|l|}{ Structure $1(n=1)$} \\
\hline $\mathrm{S}_{0}-\mathrm{S}_{1}$ & 290.2 & 4.2721 & 0.0585 & HOMO-1 LUMO & 0.9732 \\
\hline $\mathrm{S}_{0}-\mathrm{S}_{2}$ & 287.9 & 4.3068 & 0.006 & HOMO-1 LUMO & 0.97 \\
\hline $\mathrm{S}_{0}-\mathrm{S}_{3}$ & 260.7 & 4.756 & 0.0117 & HOMO-1LUMO & -0.672 \\
\hline $\mathrm{S}_{0}-\mathrm{S}_{4}$ & 260.6 & 4.7581 & 0.0005 & HOMO-1 LUMO & -0.6897 \\
\hline \multicolumn{6}{|l|}{ II $(n=2)$} \\
\hline $\mathrm{S}_{0}-\mathrm{S}_{1}$ & 330.7 & 3.7499 & 0.0867 & HOMO-2 LUMO & 0.9838 \\
\hline $\mathrm{S}_{0}-\mathrm{S}_{2}$ & 329.5 & 3.7627 & 0 & HOMO-2 LUMO & 0.9898 \\
\hline $\mathrm{S}_{\mathrm{o}}-\mathrm{S}_{3}$ & 290.3 & 4.2702 & 1.1505 & HOMO-1 LUMO & 0.9506 \\
\hline $\mathrm{S}_{0}-\mathrm{S}_{4}$ & 261.3 & 4.7516 & 0.006 & HOMO-1 LUMO & 0.6028 \\
\hline \multicolumn{6}{|l|}{ III $(n=3)$} \\
\hline$S_{0}-S_{1}$ & 346.3 & 3.5803 & 0.1485 & HOMO-2 LUMO & 0.9593 \\
\hline $\mathrm{S}_{0}-\mathrm{S}_{2}$ & 345 & 3.5934 & 0.0006 & HOMO-2 LUMO & 0.9878 \\
\hline $\mathrm{S}_{0}-\mathrm{S}_{3}$ & 318.7 & 3.8901 & 1.5623 & HOMO-2 LUMO & 0.9496 \\
\hline $\mathrm{S}_{0}-\mathrm{S}_{4}$ & 278.6 & 4.4502 & 0.0074 & HOMO-1 LUMO & 0.8453 \\
\hline \multicolumn{6}{|l|}{ IV $(n=2)$ Bridged } \\
\hline$S_{0}-S_{1}$ & 639.5 & 1.9388 & 0.0145 & HOMO LUMO & 0.9899 \\
\hline $\mathrm{S}_{0}-\mathrm{S}_{2}$ & 390.7 & 3.1733 & 0.0014 & HOMOLUMO & 0.9927 \\
\hline $\mathrm{S}_{0}-\mathrm{S}_{3}$ & 382.7 & 3.24 & 0.0003 & HOMO LUMO & 0.9942 \\
\hline $\mathrm{S}_{0}-\mathrm{S}_{4}$ & 362 & 3.4251 & 0.0003 & HOMO-2 LUMO & 0.9913 \\
\hline
\end{tabular}

Table 2: Electronic transition data for the studied compounds obtained by TD-DFT/B3LYP/6-31G (d) calculation.

electron flowing from the pyrrolyl moieties to the azaindoly moieties. The electron density distribution of HOMO and LUMO suggests that the investigated compounds might possess beneficial electron injection and transport properties with the incorporation of electron withdrawing 2-carboxylpropenoic acid group [13].

The calculated band gap (E-gap) of the studied compounds decreases in the order as follows:

I $>$ II $>$ III $>$ IV. The significant reduction of E-gap of compound IV with $2.7 \mathrm{eV}$ compared to $4.27 \mathrm{eV}$ of compound II is due to the bridging effect of $\mathrm{C}=\mathrm{C}\left(\mathrm{CO}_{2} \mathrm{H}\right)_{2}$. This bridging effect causes a destabilization of both HOMO and LUMO levels; thus, producing the lowest value of the energy gap. The low HOMO energy level of compound IV with $-5.16 \mathrm{eV}$ suggests that the compound has high oxidation stability and potential application for charge transport material [14]. For organic polymeric chromophores, this energy gap ranges from 1.4 to $3.3 \mathrm{eV}$ corresponding to light wavelength between $890-370 \mathrm{~nm}$ covering the visible region [15] (Table 2).

\section{Absorption and emission properties}

The absorption spectra of the studied compounds exhibited three absorption bands at 261-291 nm, 300-362 nm and 383-640 nm due to $\pi-\pi^{*}$ electronic transitions. The low-energy broad band at 383$640 \mathrm{~nm}$ is assigned to an intra-molecular charge transfer band from the pyrrole ring to the two 4 -azaindole backbone. The lowest-energy electronic transition HOMO $\rightarrow$ LUMO consists mostly of the intramolecular charge transfer and an average absorption band of $471 \mathrm{~nm}$. Other two absorption bands occur around $339 \mathrm{~nm}$ and $276 \mathrm{~nm}$ mainly consisting ofHOMO-2 $\rightarrow$ LUMO vertical transitions and HOMO$1 \rightarrow$ LUMOvertical transitions respectively. The excitation energy, oscillator strength, coefficient and main configuration for most relevant absorption bands were listed in Table 2. The presence of the N-H group in the heterocyclic ring influences the excited electronic states. The first four vertical excitation energies are summarized. Only two electronic transitions from ground state $\left(S_{0}\right)$ to third excited electronic state $\left(S_{3}\right)$ have computed oscillator strength been higher than 0.5 while the other electronic transitions, with smaller oscillator strength have a negligible relevance in experimental works [16-19].

\section{Conclusion}

Conjugated oligomers and polymers have been studied in great details as electroluminescent materials for usage in organic light emitting devices (OLED). Azaindolyl oligomers-based materials have been investigated extensively because of the many attractive properties they possess. Compound IV is the least sterically hindered and may be promising candidate for hole transporting and bright blue to red emitting layer in organic light emitting device (OLED) fabrication.

\section{Acknowledgments}

The authors are indebted to the department of Chemistry University of Ibadan, Ibadan Nigeria, for providing enabling environment.

\section{References}

1. Yakushchenko IK, Kaplunov MG, Efimov ON, Yu MB, Shamaev SN (1999) Polytriphenylamine derivatives as materials for hole transporting layers in electroluminescent devices. Phys Chem 1: 1783-1785.

2. Helflich W, Schneider WG (1966) Transients of Volume $\square$ Controlled Current and of Recombination Radiation in Anthracene. J Chem Phys 44, p: 2902.

3. Tang CW, Van Slyke SA (1987) Organic electroluminescent diodes. Appl Phys Lett 51: 913-915.

4. Wong KT, Chien YY, Chen RT, Wang CF Lin YT, et al (2002) $\operatorname{Ter}(9,9$ diarylfluorene)s: Highly Efficient Blue Emitter with Promising Electrochemical and Thermal Stability. J Am Chem Soc 124: 11576-11577.

5. Hong JS, Shim HS, Jae-J K, kang Y (2007) (N-7-Azaindolyl)oligothiophenes: synthesis, characterization, and photophysical properties. Tetrahedron 63 8761-8769.

6. Wu CH, Chien CH, Hsu FM, Shih PI, Shu CF (2009) Efficient non-doped bluelight-emitting diodes incorporating an anthracene derivative end-capped with fluorene groups. J Mater Chem 19: 1464-1470.

7. Wang J, Wan W, Jiang H, Gao Y, Jiang X, et al. (2010) C-9 Fluorenyl Substituted Anthracenes: A Promising New Family of Blue Luminescent Materials. Org Lett 12: 3874-3877.

8. Becke AD (1993) Densityfunctional thermochemistry. III. The role of exact exchange. J Chem Phys 98, p: 5648.

9. Kumchoo T, Promarak V, Sudyoadsuk T, Sukwattanasinitt M, Rashatasakhon $P$ (2010) Dipyrenylcarbazole Derivatives for Blue Organic Light-Emitting Diodes. Chem Asian J 5: 2162-2167. 
Citation: Ibeji CU, Okpala EO, Adejoro IA, Onyia KK (2016) Theoretical Investigation of New Organic Electroluminescent Materials Based on 4-Azaindole Groups and Oligopyrrole. J Appl Computat Math 5: 307. doi:10.4172/2168-9679.1000307

10. Lai SL, Tong QX, Chan MY, Ng TW, Lo MF, et al. (2011) Distinct electroluminescent properties of triphenylamine derivatives in blue organic light-emitting devices. Mater Chem 21: 1206-1211.

11. Sun G, Li WL, Zhao Y, Yu JQ (1996) Carrier transport in thin films of organicelectroluminescent materials. J Lumin 17, p: 91.

12. Yang SY, Kan YH, Yang GC, Su ZM, Zhao L (2006) TD-DFT investigation on the low-lying excited states of spiro-bithiophene. Chem Phys Lett 429, p: 108.

13. Khunchalee J, Tarsang R, Prachumrak N, Jungsuttiwong S, Keawin T, et al. (2012) Synthesis and properties of oligofluorene-thiophenes as emissive materials for organic electroluminescent devices: Color-tuning from deep blue to orange. Tetrahedron 68: 8416-8423.

14. Ibeji CU, Adejoro IA, Adeleke BB (2015) A Benchmark Study on the Properties of Unsubstituted and Some Substituted Polypyrroles. J Phys Chem Biophys 5: 193.

15. Adejoro IA, Akintemi E, Adeboye OO, Ibeji CC (2014) Quantum Mechanical
Studies of the Structure-activity Relationship and Electronic Vibration of Some Dietary Flavonoids. Asian Journal of Applied Sciences 7: 117-128.

16. Shi HP, Dai JX, Wua XH, Shi LW, Yuan JD, et al. (2013) A novel dimesitylboronsubstituted indolo[3,2-b]carbazole derivative: Synthesis, electrochemical photo luminescent and electroluminescent properties. Organic Electronics 14: 868-874.

17. Shimade T, Korma K, Hamaguchi A, Oluchi FS (1998) Electronic structures at the interfaces between copper phthalocyanine and layered materials. Appl Phys Lett 72, p: 1869.

18. Rottmannova L, Punyain K, Rimarcik J, Lukes V, Klein E, Kelterer AM (2012) Theoretical study of 2-phenylpyrrole molecule using various quantum-chemical approaches. Acta Chimica 5: 21-28.

19. Ibeji CU, Ghosh D (2015) Singlet-triplet gaps in polyacenes: a delicate balance between dynamic and static correlations investigated by spin-flip methods. Phys Chem Chem Phy 17: 9849-9856. 